\title{
Estimation of Yield Response Factor for Each Growth Stage under Local Conditions Using AquaCrop-OS
}

\author{
Mathias Kuschel-Otárola ${ }^{1, *}$ (D), Niels Schütze 2 (D), Eduardo Holzapfel 1,3 (D), \\ Alex Godoy-Faúndez ${ }^{3,4}$ (D), Oleksandr Mialyk ${ }^{2}$ (D) and Diego Rivera ${ }^{3,4}$ \\ 1 Department of Water Resources, School of Agricultural Engineering, University of Concepción, \\ 3812120 Chillán, Chile; eholzapf@udec.cl \\ 2 Institute of Hydrology and Meteorology, Technische Universität Dresden, 01062 Dresden, Germany; \\ niels.schuetze@tu-dresden.de (N.S.); oleksandr.mialyk@tu-dresden.de (O.M.) \\ 3 Water Research Center for Agriculture and Mining (CRHIAM), 3812120 Chillán, Chile; \\ alexgodoy@ingenieros.udd.cl (A.G.-F.); diegorivera@udd.cl (D.R.) \\ 4 Centro de Sustentabilidad y Gestión Estratégica de Recursos (CiSGER), Facultad de Ingeniería, \\ Universidad del Desarrollo, 7610658 Las Condes, Chile \\ * Correspondence: mkuschel@udec.cl
}

Received: 16 February 2020; Accepted: 4 April 2020; Published: 10 April 2020

\begin{abstract}
We propose a methodology to estimate the yield response factor (i.e., the slope of the water-yield function) under local conditions for a given crop, weather, sowing date, and management at each growth stage using AquaCrop-OS. The methodology was applied to three crops (maize, sugar beet, and wheat) and four soil types (clay loam, loam, silty clay loam, and silty loam), considering three levels of bulk density: low, medium, and high. Yields are estimated for different weather and management scenarios using a problem-specific algorithm for optimal irrigation scheduling with limited water supply (GET-OPTIS). Our results show a good agreement between benchmarking (mathematical approach) and benchmark (estimated by AquaCrop-OS) using the Normalised Root Mean Square Error (NRMSE), allowing us to estimate reliable yield response factors $(K y)$ under local conditions and to dispose of the typical simple mathematical approach, which estimates the yield reduction as a result of water scarcity at each growth stage.
\end{abstract}

Keywords: AquaCrop-OS; crop yield function; yield response factor; growth stages

\section{Introduction}

Water is the main factor for crop development. Globally, irrigation in agriculture uses about $70 \%$ of the available fresh water resources [1] and so, improving irrigation management will increase the water use efficiency (WUE), which is defined as the amount of water necessary to achieve a given yield [2]. According to Saccon [3], the effective planning and management of water for crop production requires a deep knowledge of the system, as experimental results are generally site-specific and are not applicable to different weather, soil, crop, and management conditions. Furthermore, carrying out field experiments is expensive, laborious [4], and time-consuming.

To address the above concerns, the Food and Agriculture Organization (FAO) of the United Nations has developed the AquaCrop model [5]. This model simulates attainable yields of crops as a function of water consumption under rain-fed, supplemental, deficit, and full irrigation conditions, and has been used to accurately determine crop yields in maize [6-8], wheat [9-11], sugar beet [4,12,13], potatoes [14,15], barley [16], quinoa [17], and rice [18]. AquaCrop has also been linked to crop production functions [19-27] which relate yield reduction as a result of the relative loss in evapotranspiration [28]. 
For yield reduction due to water stress, Doorenbos and Kassam [20] proposed:

$$
1-\frac{Y}{Y m}=K y\left(1-\frac{E T a}{E T c}\right),
$$

where $Y$ and $Y m$ are the actual and maximum crop yields, respectively; ETa and ETc correspond to actual and maximum evapotranspiration, respectively; and the coefficient $\mathrm{Ky}$ denotes the yield response factor, which relates the yield reduction $\left(1-Y / Y_{m}\right)$ to the water stress $\left(1-E T_{a} / E T_{\mathcal{c}}\right)$ for a given environment [23].

In the literature, researchers have developed a multiplicative approach to the equation proposed by Doorenbos and Kassam $[20,23,27,29]$. This approach relates the crop yield reduction as a function of the water stress at specific growth stages. According to Shrestha et al. [30], with the rise in average yields and an increase in crop sensitivities to water stress, the Ky coefficients need to be updated. In the literature, $K y$ values have been estimated for maize, wheat, and sugar beet. For maize, Kresović et al. [31] have assessed the effects of different irrigation amounts, estimating grain yield functions depending on seasonal irrigation and water consumption. The latter depends seasonally on $K y$. Djaman et al. [32] have measured and evaluated crop response to several variables under different levels of irrigation, quantifying seasonal values of $\mathrm{Ky}$. With respect to sugar beet, Kiymaz and Ertek [33] have determined the effect of different irrigation and nitrogen levels on yield and other components, obtaining $\mathrm{Ky}$ for two growing seasons. Tarkalson et al. [34] have quantified the yield response to water input and actual evapotranspiration; they also obtained $K y$ for two growing seasons. Regarding wheat, Bandyopadhyay et al. [35] have analysed the effect of different combinations of sprinkler and surface flooding on crop production functions, obtaining $\mathrm{Ky}$ for each irrigation treatment and Liu et al. [36] have evaluated the performance of winter wheat under different irrigation amounts, estimating $\mathrm{Ky}$ for four growing seasons.

Foster et al. [37] developed the AquaCrop-OS model, an open-source code written in MATLAB, providing the opportunity to link it with other concepts to assess farming scenarios. Considering the importance of the sub-seasonal application of water in food production, we defined the following research question: Is it possible to incorporate the multiplicative approach of Doorenbos and Kassam [20] into AquaCrop-OS, in order to estimate Ky at each growth stage? Therefore, the main objective of our research was to develop and test a methodology to estimate Ky under local conditions for a given crop, soil, weather, sowing date, and management at each growth stage using AquaCrop-OS. Reliable Ky values under local conditions for each growth stage allow farmers to decrease uncertainty and improve risk management due to intraseasonal changes.

\section{Methodology}

Our proposed methodology aims to include the AquaCrop-OS model into the multiplicative approach of Doorenbos and Kassam [20], with the objective of determining Ky under local conditions (i.e., for a given crop, soil, weather, sowing date, and management) at each growth stage.

\subsection{Crop Yield Equation}

The multiplicative approach of the equation proposed by Doorenbos and Kassam [20] (Equation (1)) is:

$$
\frac{Y}{Y m}=\prod_{n=1}^{N}\left[1-K y_{n}\left(1-\frac{E T a_{n}}{E T c_{n}}\right)\right],
$$

where $n$ is an index representing each growth stage and $N$ corresponds to the number of functions between the square brackets [23]. 


\subsection{Estimation of Ky Using AquaCrop-OS}

This section was developed in MATLAB and is split into two parts: A benchmark definition and a benchmarking (Figure 1).

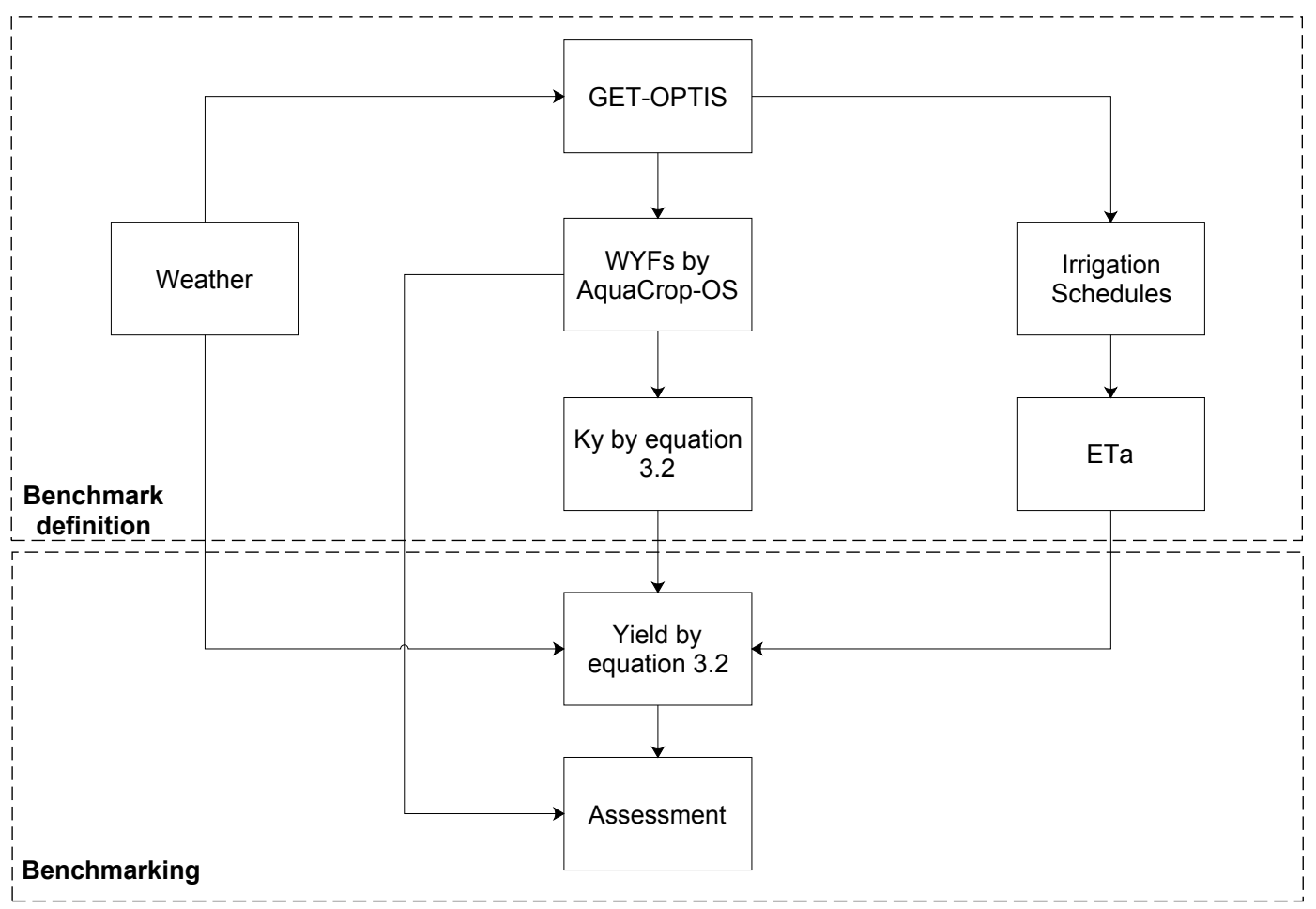

Figure 1. The methodology used for this research to estimate the Ky value at each growth stage under local conditions (i.e., for a given crop, soil, weather, sowing date, and management) using AquaCrop-OS.

As a benchmark definition, we started with a database of historical weather scenarios for a given area in which, for each year, the water-yield functions (WYF) have been determined using AquaCrop-OS [37] and a problem-specific algorithm for optimal irrigation scheduling with limited water supply. This is named the Global Evolutionary Technique for OPTimal Irrigation Scheduling (GET-OPTIS) [24]. The main objective of GET-OPTIS is to maximise the crop yield $(Y)$ by finding an optimal irrigation schedule $(S)$ composed of a date $\left(d_{i}\right)$ and an irrigation depth $\left(v_{i}\right)$ (Figure 2):

$$
\begin{aligned}
Y^{*} & =\max Y(S): S=\left\{s_{i}\right\}_{i=1 \ldots n} \\
& =\left\{\left(d_{1}, v_{1}\right), \ldots,\left(d_{i}, v_{i}\right), \ldots,\left(d_{n}, v_{n}\right)\right\} n, d_{i} \in \mathbb{N} ; v_{i} \in \mathbb{R} .
\end{aligned}
$$

This process required high computational effort, as building 34,020 scenarios (21 points for 45 years, 3 crops, and 12 soil types) was required. So, we used the parallel run mode in MATLAB R2017a [38]. Parallel computing allows us to carry out many calculations simultaneously, accelerating the computing speed. Once the WYFs were built, the Ky values (i.e., the slopes of the WYFs) were estimated, by considering Equation (2), through the least square method at each growth stage: (1) emergency or transplant recovery, (2) vegetative stage, (3) flowering stage, and (4) yield formation and ripening [39]. Finally, we considered discrete mean values of Ky every 5 years. It should be noted that there were no measured data used in this case, and the simulation results from AquaCrop-OS were used as the comparison benchmark for evaluation. 

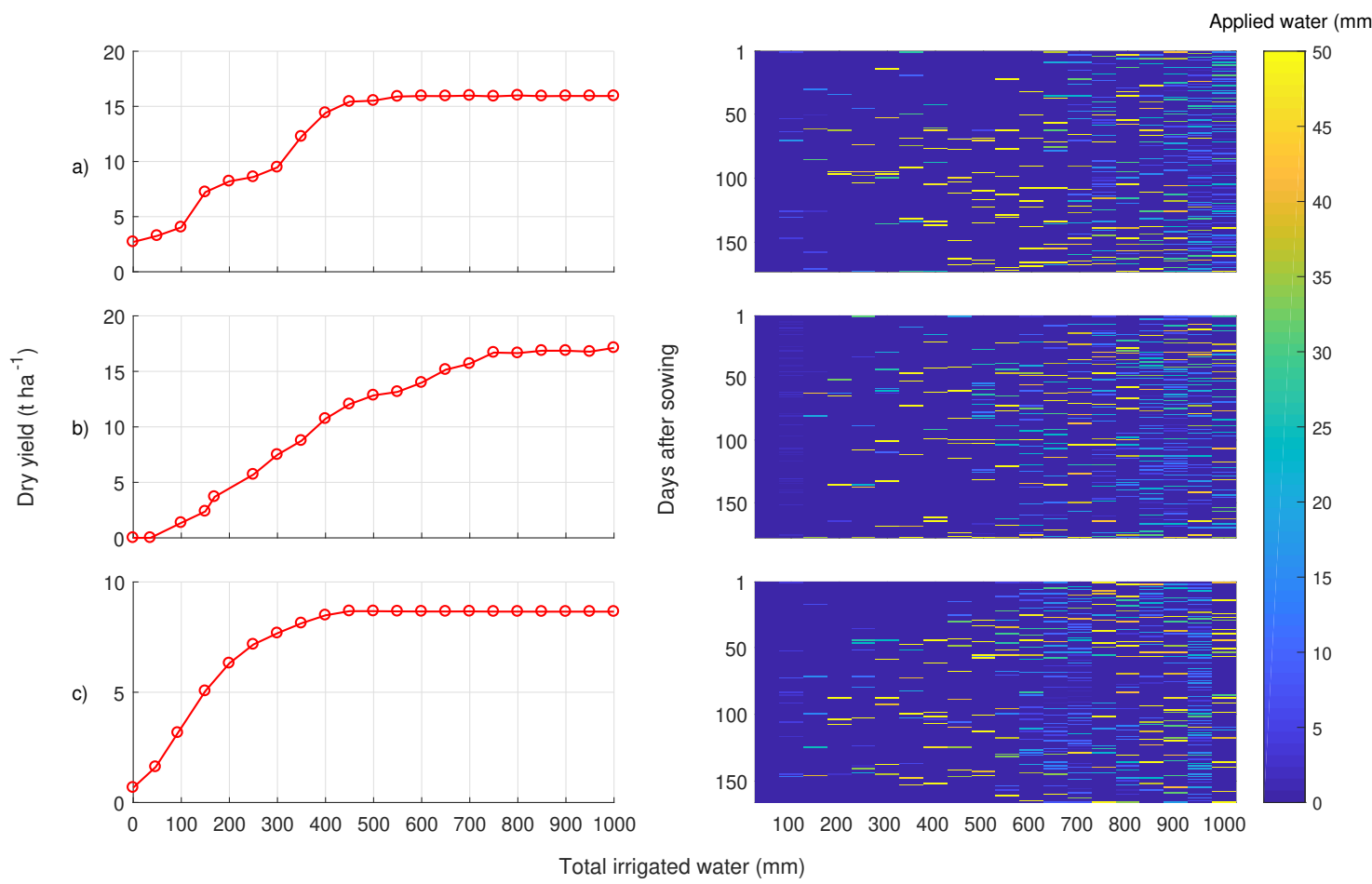

Figure 2. Water-yield functions (left side) and optimal irrigation schedules (right side) for maize (a), sugar beet (b), and wheat (c) under clay loam soil conditions.

Benchmarking was carried out by determining crop yield using Equation (2), considering the Ky values for each combination of crop, soil type, and weather scenario for each year. Different statistical indices were used, such as Normalised Root Mean Square Error (NRMSE) and linear regression, for comparison of the results obtained from AquaCrop-OS and those estimated using the proposed methodology. The NRMSE (in \%) was calculated according to Loague and Green [40]:

$$
\text { NRMSE }=\left[\sqrt{\frac{\sum_{s=1}^{S}\left(Y_{A O S, k}-Y_{\text {Prop }, k}\right)^{2}}{S}}\right] \times \frac{100}{\overline{Y_{A O S, k}}},
$$

where $Y_{A O S, k}$ and $Y_{\text {Prop, } k}$ correspond respectively to the crop yield estimated by AquaCrop-OS and the proposed methodology for the year $k$ and $\overline{Y_{A O S, k}}$ represents the mean value of the crop yields estimated by AquaCrop-OS for the year $k$. A simulation is considered excellent if its NRMSE is less than $10 \%$, good if its NRMSE is greater than $10 \%$ and less than $20 \%$, fair if its NRMSE is greater than $20 \%$ and less than $30 \%$, and poor if its NRMSE is greater than $30 \%$ [ 41 ].

\subsection{Case Study}

Our proposed model was applied to conditions characteristic of the Central Valley of Chile (see Figure 3). The annual mean precipitation in this area is about $1025 \mathrm{~mm}$, and the average maximum and minimum temperatures are 20.6 and $7.6{ }^{\circ} \mathrm{C}$, respectively [42]. This region contains about $28 \%$ of the national cropping area. Some of the most-produced crops are wheat $(34.3 \%)$, maize $(11.6 \%)$, and sugar beet $(6 \%)$, which contribute to $27.9 \%, 22.5 \%$, and $60 \%$ of the national planted surface, respectively [ 43 ]. The soils are formed from volcanic ashes (Andisols) deposited over an unrelated substrate of andesitic tuff and fluvioglacial materials. The texture is predominately silty clay loam, silty loam, and loam, and the bulk density ranges from 0.71 to $1.35 \mathrm{Mg} \mathrm{m}^{-3}$ [44-46]. 


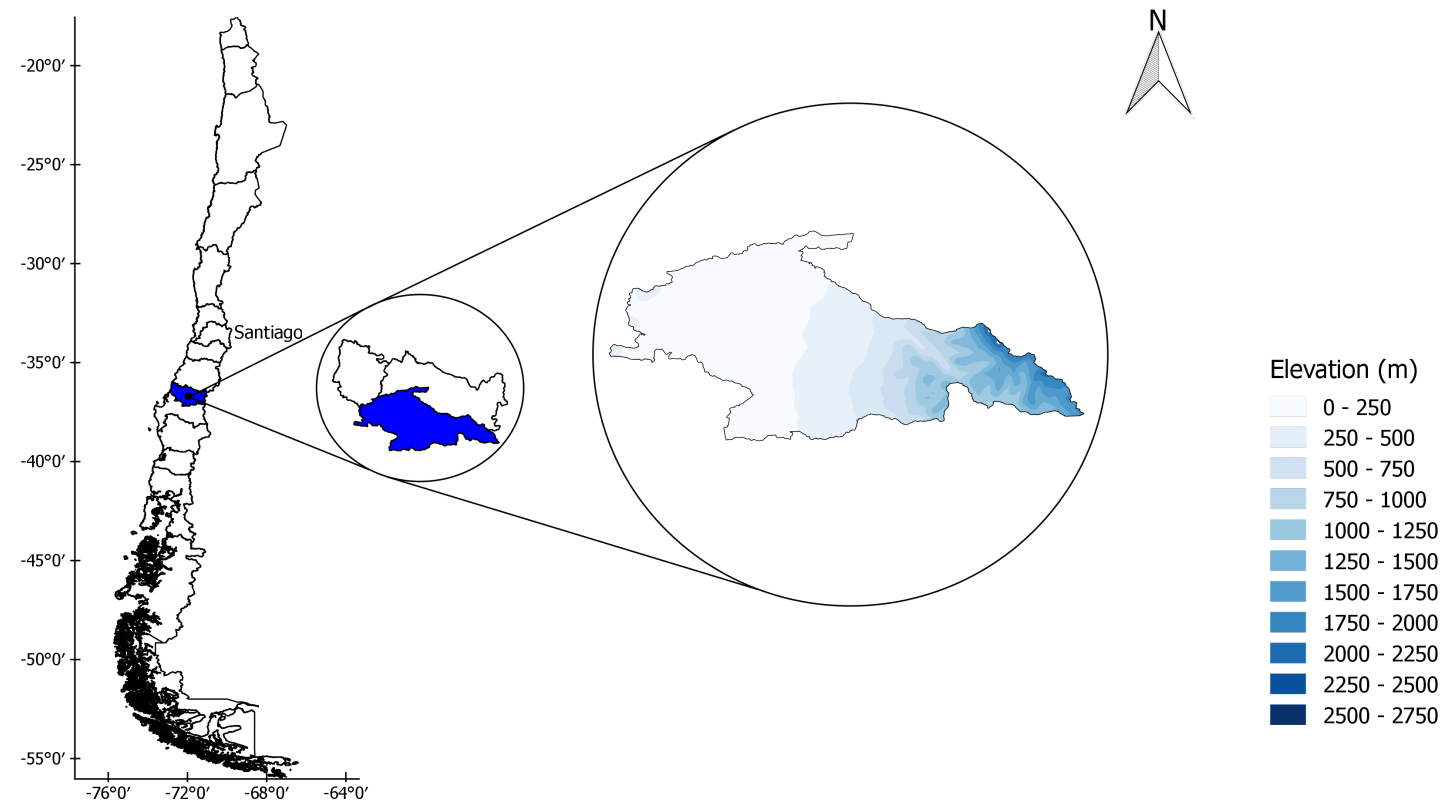

Figure 3. Study area location.

\subsection{Model Inputs}

Sowing dates for maize, wheat, and sugar beet for each year correspond to the first day of November, September, and August, respectively [47]. A weather database from 1970 to 2014 (Figure 4) was extracted from the Explorador Climático website (http:/ / explorador.cr2.cl/). Reference evapotranspiration was estimated according to Allen et al. [48]. Crop parameters from the AquaCrop-OS [37] database were considered (see Table 1). On the other hand, soil hydraulic parameters (Table 2) were extracted from Granda et al. [45] and saturated hydraulic conductivity (Ks) was estimated using the RETC model [49]. Soils in the area of study are mainly derived from volcanic ashes, with strong vertical and horizontal variability. The data in Table 2 are based on field studies (see Granda et al. [45] and Kuschel-Otárola [50]), such that the Ks values lie in the range of variation and provide realistic values for representative soils. However, we draw attention to the fact that andesitic soils are less-studied soils and show high variability in hydraulic parameters, despite having similar texture. Moreover, agricultural operations have effects on changes in bulk density which are not always accounted by pedotransfer functions. For soils, the numbers 1, 2, and 3 correspond to low, medium, and high bulk density, respectively. Each growing season started with $50 \%$ of the total available water. Regarding fertilisation, there was no differentiated management to not alter the water management conditions. 

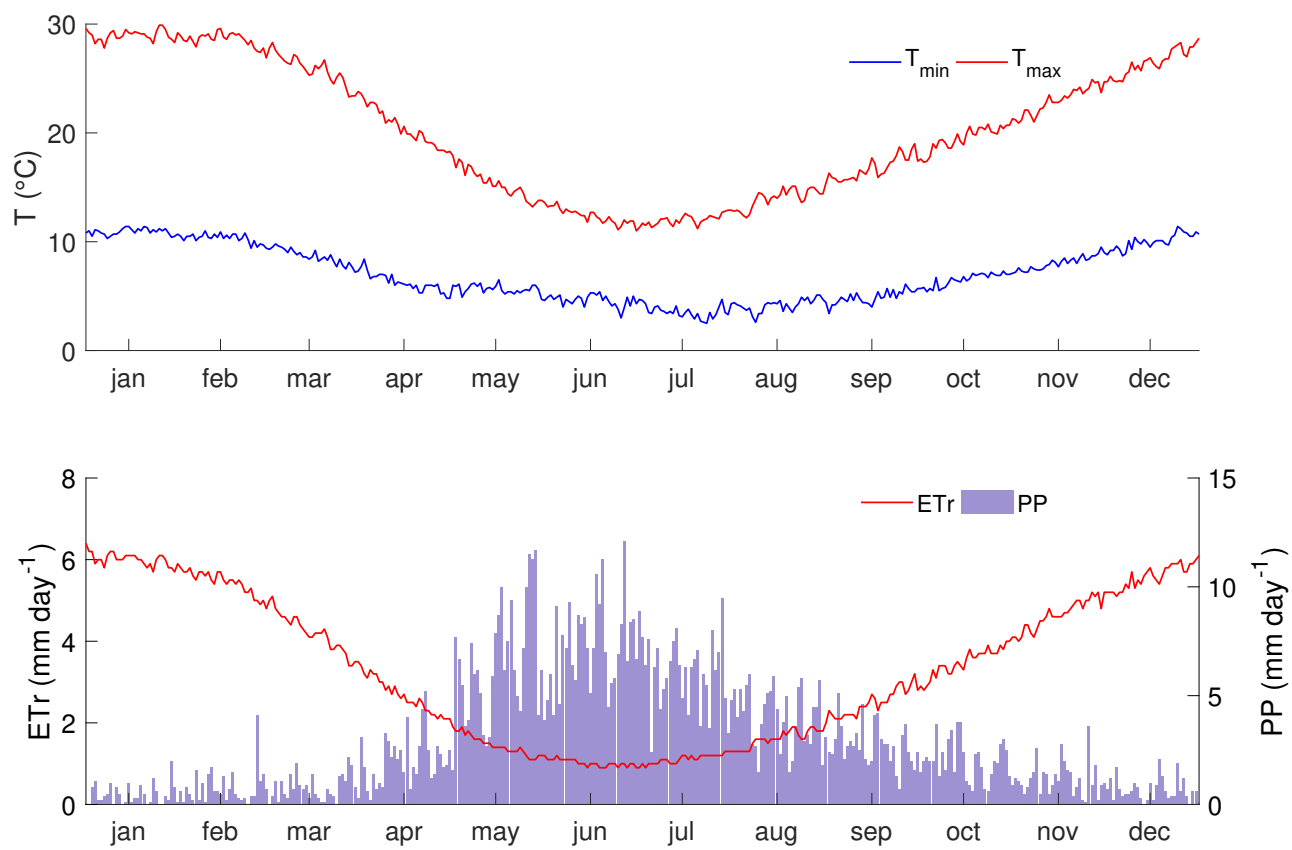

Figure 4. Minimum and maximum temperature $\left(T_{\min }\right.$ and $\left.T_{\max }\right)$, reference evapotranspiration $(E T r)$, and precipitation $(P P)$ for the study area, presented as mean values from 1970 to 2014.

Table 1. Conservative (constant) and generally applicable parameters for maize, sugar beet, and wheat in the Central Valley of Chile.

\begin{tabular}{|c|c|c|c|}
\hline \multirow{2}{*}{ Parameter } & \multicolumn{3}{|c|}{ Crop } \\
\hline & Maize & Sugar Beet & Wheat \\
\hline \multicolumn{4}{|l|}{ Conservative (generally applicable) } \\
\hline Base temperature $\left({ }^{\circ} \mathrm{C}\right)$ & 8.00 & 5.00 & 0.00 \\
\hline Cut-off temperature $\left({ }^{\circ} \mathrm{C}\right)$ & 30.00 & 30.00 & 26.00 \\
\hline Canopy cover per seedling at $90 \%$ emergence $\left(\mathrm{CC}_{\mathrm{o}}\right)$ & 6.50 & 1.00 & 1.50 \\
\hline Canopy growth coefficient (CGC) & 1.25 & 1.05 & 0.50 \\
\hline Maximum canopy cover (CCx) & 96.00 & 98.00 & 96.00 \\
\hline Crop coefficient for transpiration at CC $=100 \%$ & 1.05 & 1.10 & 1.10 \\
\hline Decline in crop coef. after reaching CCx & 0.30 & 0.15 & 0.15 \\
\hline Canopy decline coefficient (CDC) at senescence & 1.00 & 0.39 & 0.40 \\
\hline Water productivity, normalised to the year $2000\left(\mathrm{WP}^{*}\right)$ & 33.70 & 17.00 & 15.00 \\
\hline Leaf growth threshold $\left(\mathrm{P}_{\text {upper }}\right)$ & 0.14 & 0.20 & 0.20 \\
\hline Leaf growth threshold $\left(\mathrm{P}_{\text {lower }}\right)$ & 0.72 & 0.60 & 0.65 \\
\hline Leaf growth stress coefficient curve shape & 2.90 & 3.00 & 5.00 \\
\hline Stomatal conductance threshold $\left(\mathrm{P}_{\text {upper }}\right)$ & 0.69 & 0.65 & 0.65 \\
\hline Stomata stress coefficient curve shape & 6.00 & 3.00 & 2.50 \\
\hline Senescence stress coefficient $\left(\mathrm{P}_{\text {upper }}\right)$ & 0.69 & 0.75 & 0.70 \\
\hline Senescence stress coefficient curve shape & 2.70 & 3.00 & 2.50 \\
\hline \multicolumn{4}{|l|}{ Considered to be conservative but can or may be cultivar-specific } \\
\hline Reference harvest index $\left(\mathrm{HI}_{\mathrm{O}}\right)$ & 48 & 70 & 48 \\
\hline GDD from $90 \%$ emergence to start of anthesis & 800 & 842 & 1100 \\
\hline Duration of anthesis, in GDD & 180 & 0 & 200 \\
\hline Coefficient, inhibition of leaf growth on HI & 7 & 4 & 10 \\
\hline Coefficient, inhibition of stomata on HI & 3 & - & 7 \\
\hline Maximum yield ( $\mathrm{t} \mathrm{ha}^{-1}$ ) (more details in Kuschel-Otárola et al. [27]) & 15 & 100 & 7 \\
\hline
\end{tabular}


Table 2. Bulk density $\left(\rho_{a}\right)$, saturation $\left(\theta_{s}\right)$, field capacity $\left(\theta_{f c}\right)$, permanent wilt water content $\left(\theta_{\text {pwp }}\right)$, and saturated hydraulic conductivity $\left(K_{s}\right)$ representative of the Central Valley of Chile. A constant soil depth of $2.3 \mathrm{~m}$ was considered and there was no influence from the water table.

\begin{tabular}{|c|c|c|c|c|c|c|c|c|}
\hline Soil & Sand & $\begin{array}{l}\text { Silt } \\
(\%)\end{array}$ & Clay & $\begin{array}{c}\rho_{a} \\
\left(\mathrm{~g} \mathrm{~cm}^{-3}\right)\end{array}$ & $\theta_{s}$ & $\begin{array}{c}\theta_{f c} \\
\left(\mathrm{~m}^{3} \mathrm{~m}^{-3}\right)\end{array}$ & ${ }^{3} \theta_{p w p}$ & $\begin{array}{c}K_{s} \\
\left(\mathrm{~mm} \mathrm{day}^{-1}\right)\end{array}$ \\
\hline ClayLoam 1 & 22 & 48 & 30 & 0.72 & 0.73 & 0.45 & 0.30 & 3415.9 \\
\hline ClayLoam 2 & 35 & 38 & 27 & 0.97 & 0.64 & 0.57 & 0.33 & 269.1 \\
\hline ClayLoam 3 & 39 & 28 & 33 & 1.39 & 0.47 & 0.34 & 0.26 & 132.4 \\
\hline Loam 1 & 34 & 42 & 24 & 0.71 & 0.73 & 0.44 & 0.28 & 3517.8 \\
\hline Loam 2 & 31 & 46 & 23 & 1.07 & 0.60 & 0.59 & 0.40 & 69.5 \\
\hline Loam 3 & 41 & 37 & 22 & 1.13 & 0.57 & 0.55 & 0.34 & 110.3 \\
\hline SiltyClayLoam 1 & 10 & 52 & 38 & 0.78 & 0.70 & 0.46 & 0.32 & 2382.0 \\
\hline SiltyClayLoam 2 & 11 & 52 & 37 & 0.81 & 0.69 & 0.50 & 0.32 & 1903.3 \\
\hline SiltyClayLoam 3 & 15 & 49 & 36 & 0.86 & 0.68 & 0.50 & 0.36 & 1534.2 \\
\hline SiltyLoam 1 & 27 & 50 & 23 & 0.71 & 0.73 & 0.44 & 0.28 & 3571.7 \\
\hline SiltyLoam 2 & 22 & 51 & 27 & 0.98 & 0.63 & 0.59 & 0.38 & 183.9 \\
\hline SiltyLoam 3 & 24 & 51 & 25 & 1.03 & 0.61 & 0.59 & 0.44 & 76.3 \\
\hline
\end{tabular}

\section{Results and Discussions}

\subsection{Yield Response Factor for Each Growth Stage}

The $K y$ values for each growth stage (emergency or transplant recovery, vegetative stage, flowering stage, and yield formation and ripening) are presented in form of box plots for maize, sugar beet, and wheat, in Figures 5-7, respectively. These figures represent $\mathrm{Ky}$ as a discrete mean value over 5 years for benchmarking (i.e., 1970-1974, 1975-1979, 1980-1984, 1985-1989, 1990-1994, 1995-1999, 2000-2004, 2005-2009, and 2010-2014) for different soil types in the study area with low (1), medium (2), and high (3) bulk densities (Table 2) considering optimal irrigation scheduling (GET-OPTIS). In each box, the central mark indicates the median, and the bottom and top edges of the box indicate the 25th and 75th percentiles, respectively. The whiskers extend to the most extreme data points not considered as outliers, and the outliers are plotted individually using the " + " symbol.

\subsubsection{Yield Response Factor For Maize}

Figure 5 shows the Ky values for maize at each growth stage and for soils with low (1), medium (2), and high (3) bulk densities. According to Steduto et al. [28], $K y>1$ implies that the crop is very sensitive to water deficits, $K y<1$ means that it is more tolerant to water deficits, and $K y=1$ corresponds to a direct proportion of yield reduction to reduced water use. The Ky value for the first growth stage was close to zero for all soil types. On the other hand, $K y$ always reached its maximum in the third growth stage (flowering). Its values ranged from 0.9 to 1.4 , indicating that maize is very sensitive to water deficits in this stage. Thus, water stress during this stage incurs larger reductions than in other stages [20,28]. For clay loam soil, the higher the bulk density, the lower the value of $K y$ was in the third growth stage. With the exception of the fourth growth stage, the obtained values were lower than those proposed by the FAO [51].

\subsubsection{Yield Response Factor for Sugar Beet}

Figure 6 shows the $K y$ values for sugar beet at each growth stage and for each soil type. Similarly to the results obtained for maize (Figure 5), the Ky value in the first growth stage was close to zero for all soil types, indicating that yield is not affected when there is enough water in the soil profile. It reached its maximum value in the third growth stage for most soil types; except for clay loam soil with high bulk density, where this value was the lowest (compared with the other soil types). 
Furthermore, this soil type presented the highest values for the second and fourth growth stage. The obtained values were lower than those proposed by the FAO [51], for each growth stage.
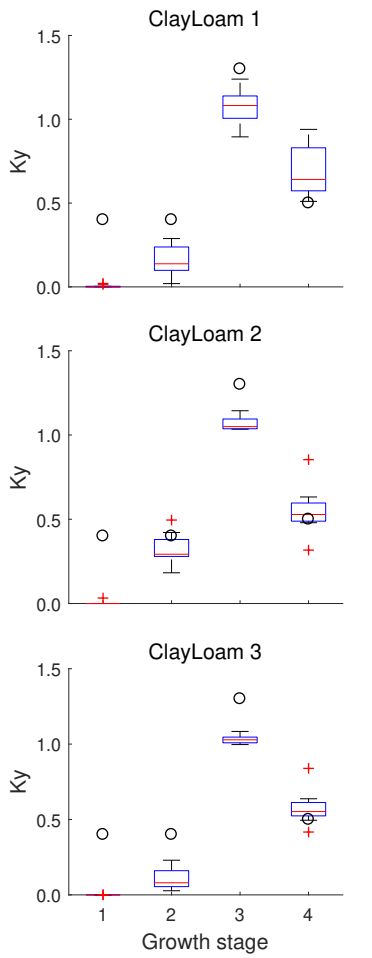
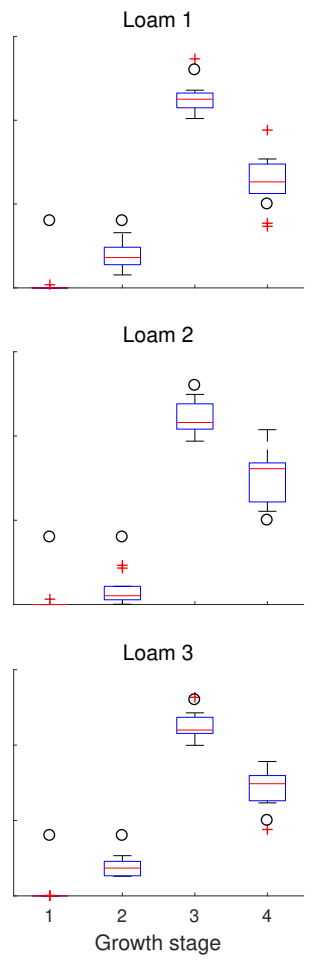

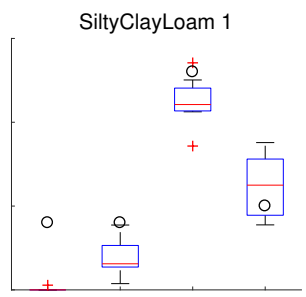

SiltyClayLoam 2

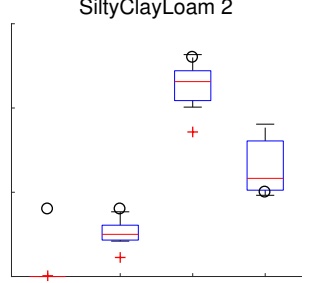

SiltyClayLoam 3

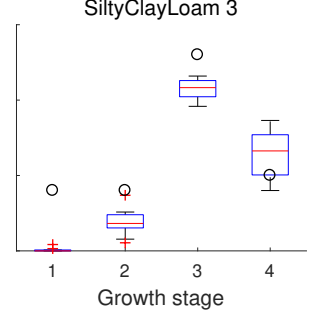

SiltyLoam

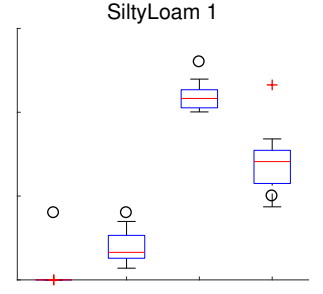

SiltyLoam 2

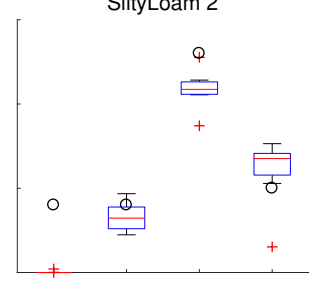

SiltyLoam 3

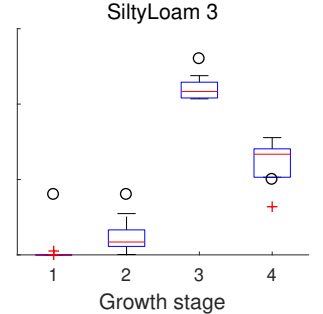

Figure 5. Yield response factor $(K y)$ obtained for maize for every soil type, considering the benchmark process. Circles represent $K y$ values proposed by the FAO [51].
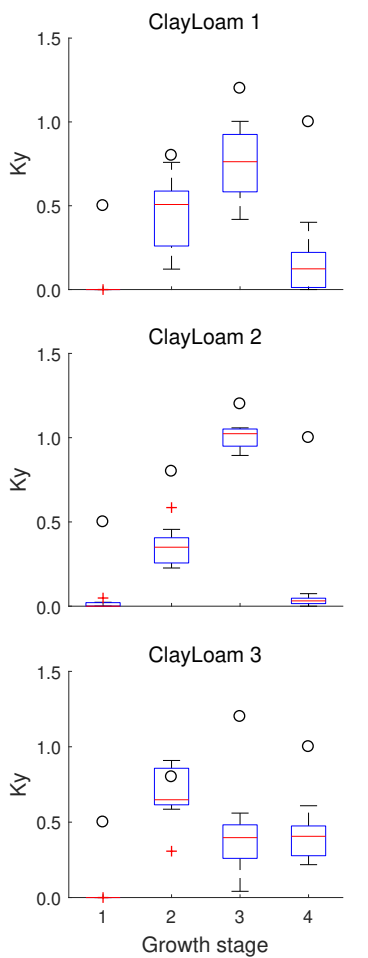
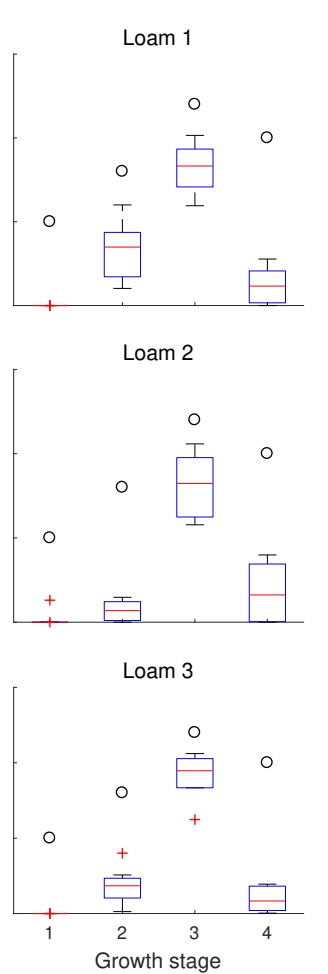

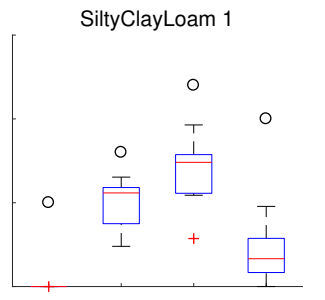

SiltyClayLoam 2

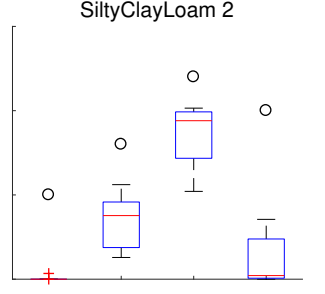

SiltyClayLoam 3

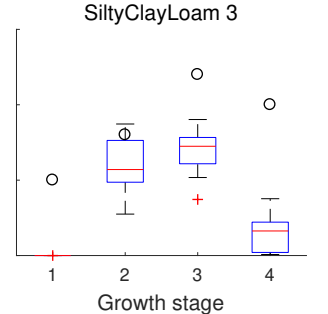

SiltyLoam 1

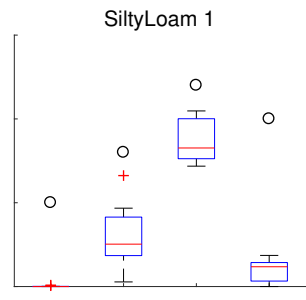

SiltyLoam 2

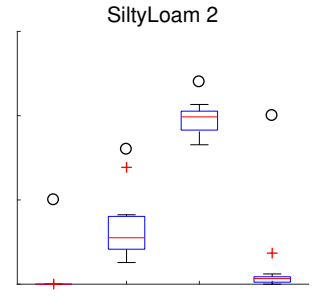

SiltyLoam 3

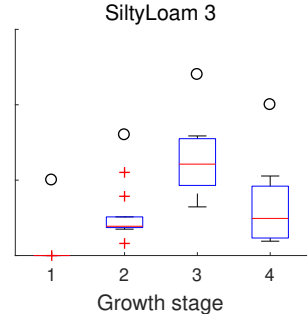

Figure 6. Yield response factor $(K y)$ obtained for sugar beet for every soil type, considering the benchmark process. Circles represent $K y$ values proposed by the FAO [51]. 


\subsubsection{Yield Response Factor For Wheat}

Figure 7 shows the $K y$ values for wheat for each growth stage and for each soil type. Similarly to the results obtained for maize (Figure 5) and sugar beet (Figure 6), the Ky value in the first growth stage was close to zero, except for loam soil with medium bulk density $(K y=0.15)$. Regarding the value for the third growth stage, this value was relatively low when compared to maize and sugar beet. The lowest value for the third growth stage was presented in loam soil with medium bulk density $(K y=0.73)$; this soil type also presented a value over the 70th percentile for the second growth stage $(K y=0.30)$. With the exception of the third growth stage, the obtained values were lower than those proposed by the FAO [51]. Soils with high bulk density (index number 3) showed lower differences, with respect to the values proposed in the literature.
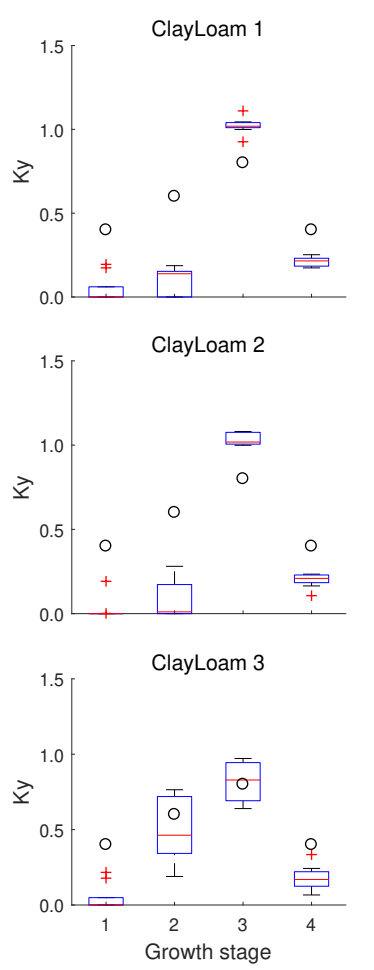
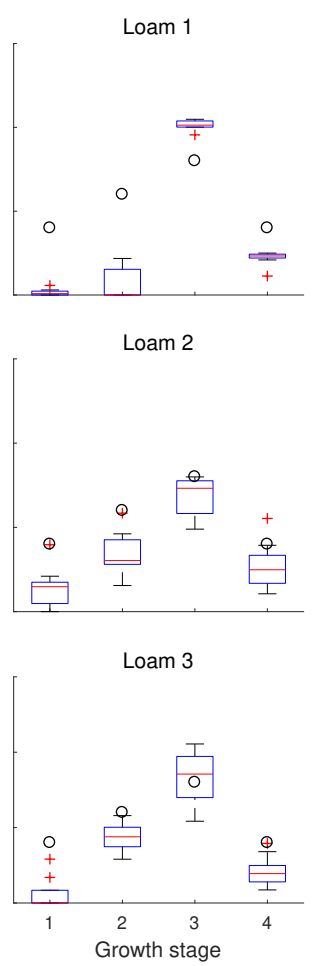

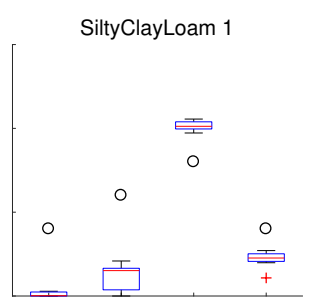

SiltyClayLoam 2

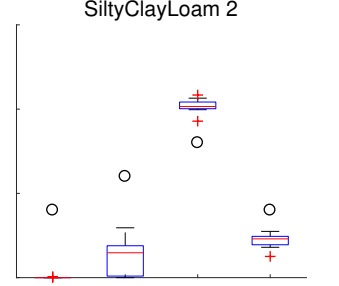

SiltyClayLoam 3

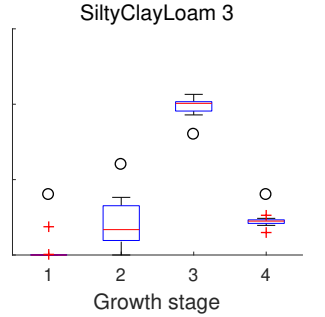

SiltyLoam 1

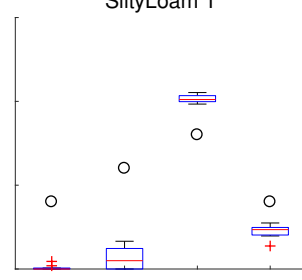

SiltyLoam 2

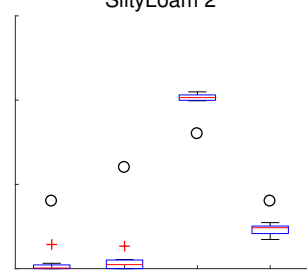

SiltyLoam 3

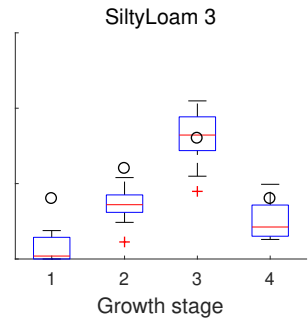

Figure 7. Yield response factor $(K y)$ obtained for wheat for every soil type considering the benchmark process. Circles represent $K y$ values proposed by the FAO [51].

\subsection{Benchmarking of the Proposed Methodology}

\subsubsection{Benchmarking for a Specific Year}

Figure 8 shows the comparison between the dry yield obtained by AquaCrop-OS (red line 1:1) and the estimates obtained by the proposed methodology (blue dots). There was generally a good agreement between the results obtained by AquaCrop-OS and the proposed methodology, with NRMSE values ranging from $1.62 \%$ (wheat in a silty loam soil) to $15.80 \%$ (sugar beet in a loam soil). The Ky values used in this case were extracted from the benchmark between 2010-2014 (see Table 3). According to Steduto et al. [28], sugar beet (Beta vulgaris) is a biennial plant which produces a large storage root as a part of its tap root, containing $14-20 \%$ sucrose on a fresh mass basis; thus, the crop yield values of sugar beet can reach $80-120 \mathrm{tha}^{-1}$.

\subsubsection{Benchmarking for All Years}

The benchmarking for all years was carried out by determining the Normalised Root Mean Square Error (NRMSE) for every year. Figure 9 shows the NRMSE values for each year for maize (a), sugar beet 
(b), and wheat (c), for all soil types, where the lowest and highest values are presented in blue and red, respectively. According to the classification suggested by Jamieson et al. [41], the values are ranged from $0 \%$ to $\geq 30 \%$. It can be seen that wheat presented the best performance.
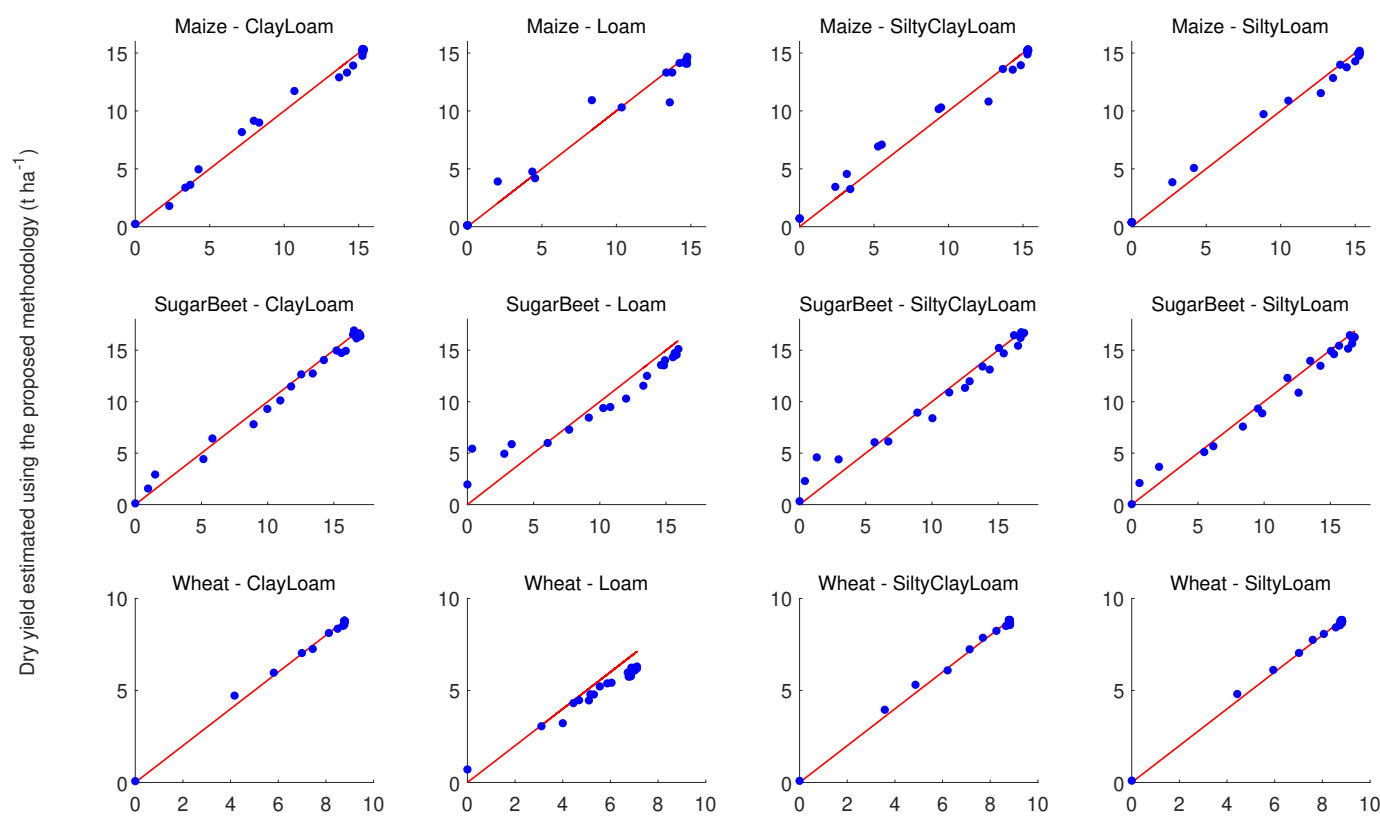

Dry yield obtained from AquaCrop-OS $\left(\mathrm{t} \mathrm{ha}^{-1}\right)$

Figure 8. Crop yield ( $\mathrm{Y}$ ) obtained from the benchmarking for maize, sugar beet, and wheat in various soil types considering the mean value of bulk density in the year 2014. Red lines present the benchmark estimated by AquaCrop-OS, while each blue dot corresponds to the crop yield estimated by the proposed methodology.

Table 3. Yield response factor $(K y)$ obtained for maize, sugar beet, and wheat in various soil types considering the mean value of bulk density, valid for the years 2010-2014.

\begin{tabular}{clccccc}
\hline Crop & \multicolumn{1}{c}{ Soil } & 1st & 2nd & 3rd & 4th & Total \\
\hline \multirow{4}{*}{ Maize } & ClayLoam & 0.00 & 0.29 & 1.04 & 0.48 & 1.07 \\
& Loam & 0.00 & 0.05 & 0.97 & 0.73 & 1.01 \\
& SiltyClayLoam & 0.00 & 0.22 & 0.86 & 0.58 & 1.10 \\
& SiltyLoam & 0.00 & 0.47 & 1.05 & 0.15 & 1.10 \\
\hline \multirow{5}{*}{ Sugar beet } & ClayLoam & 0.00 & 0.59 & 1.02 & 0.00 & 1.16 \\
& Loam & 0.00 & 0.12 & 0.82 & 0.21 & 1.13 \\
& SiltyClayLoam & 0.00 & 0.51 & 0.96 & 0.00 & 1.15 \\
\multirow{5}{*}{ Wheat } & SiltyLoam & 0.00 & 0.41 & 1.00 & 0.00 & 1.16 \\
& ClayLoam & 0.00 & 0.00 & 1.01 & 0.23 & 1.05 \\
& Loam & 0.16 & 0.40 & 0.73 & 0.26 & 1.09 \\
& SiltyClayLoam & 0.00 & 0.00 & 1.01 & 0.25 & 1.09 \\
& SiltyLoam & 0.00 & 0.00 & 1.02 & 0.25 & 1.04 \\
\hline
\end{tabular}

On the other hand, Figure 10 shows a comparison of the frequency of NRMSE values, as suggested by Jamieson et al. [41]. Local estimation of the Ky values presented better performance, compared to the values reported in the literature [20,51], as they were not specific to a particular soil type or management. Local estimation increased the frequency of the best performance (excellent) in maize (from 0 to $67 \%$ ), sugar beet (from 0 to 35\%) and wheat (from 46 to $82 \%$ ). Wheat, however, presented the best performance, considering the $K y$ values suggested by the FAO [51]. 
a)

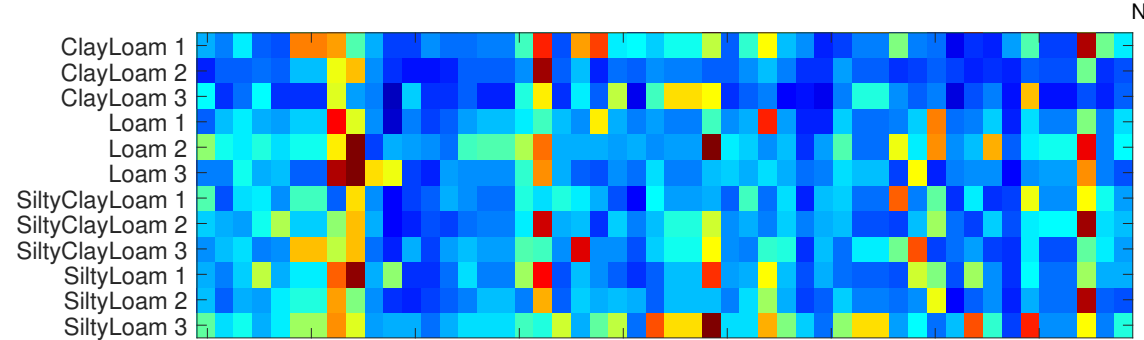

NRMSE (\%)

b)
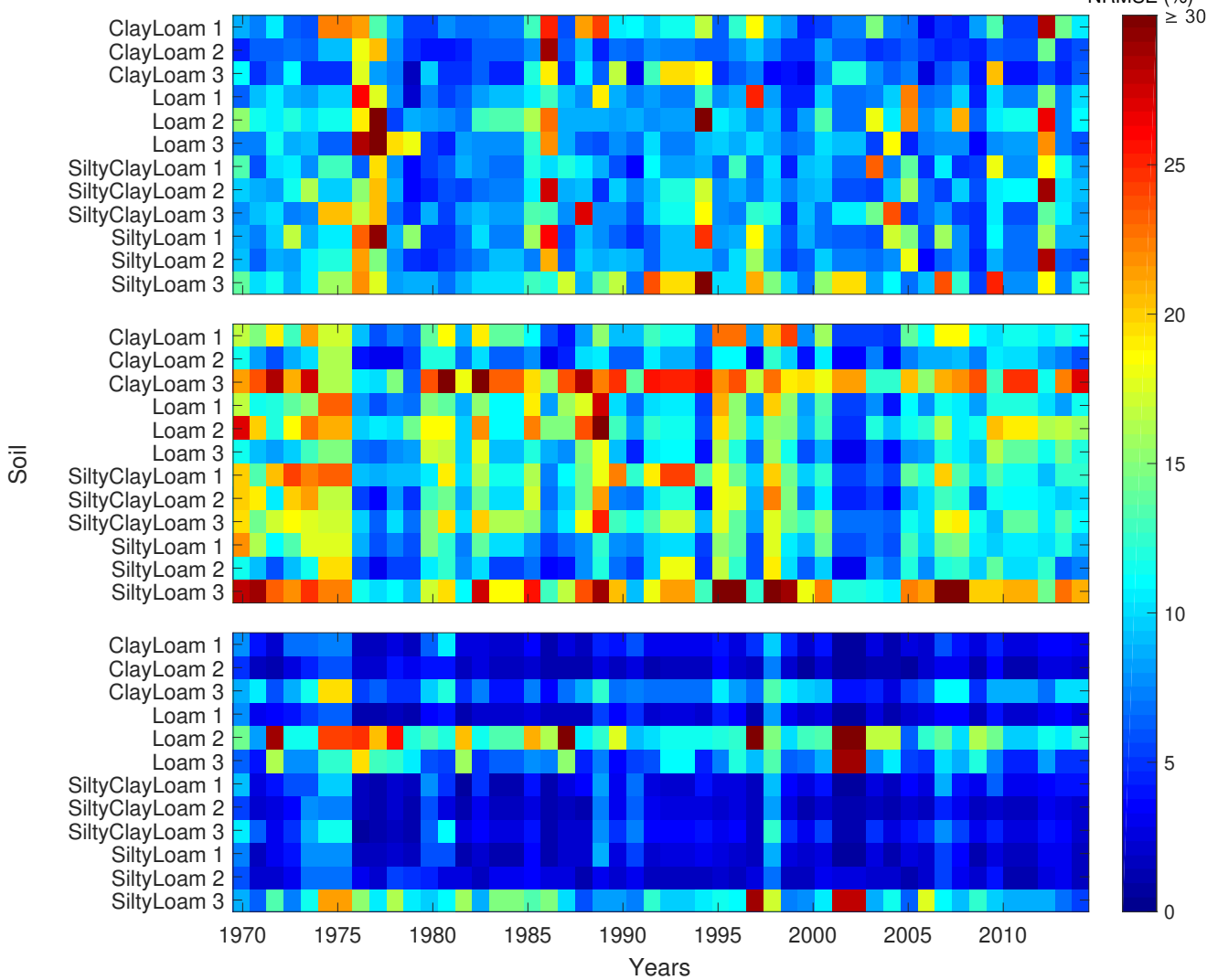

Figure 9. Normalised Root Mean Square Error (NRMSE) for maize (a), sugar beet (b), and wheat (c), for every soil type, from 1970 to 2014.

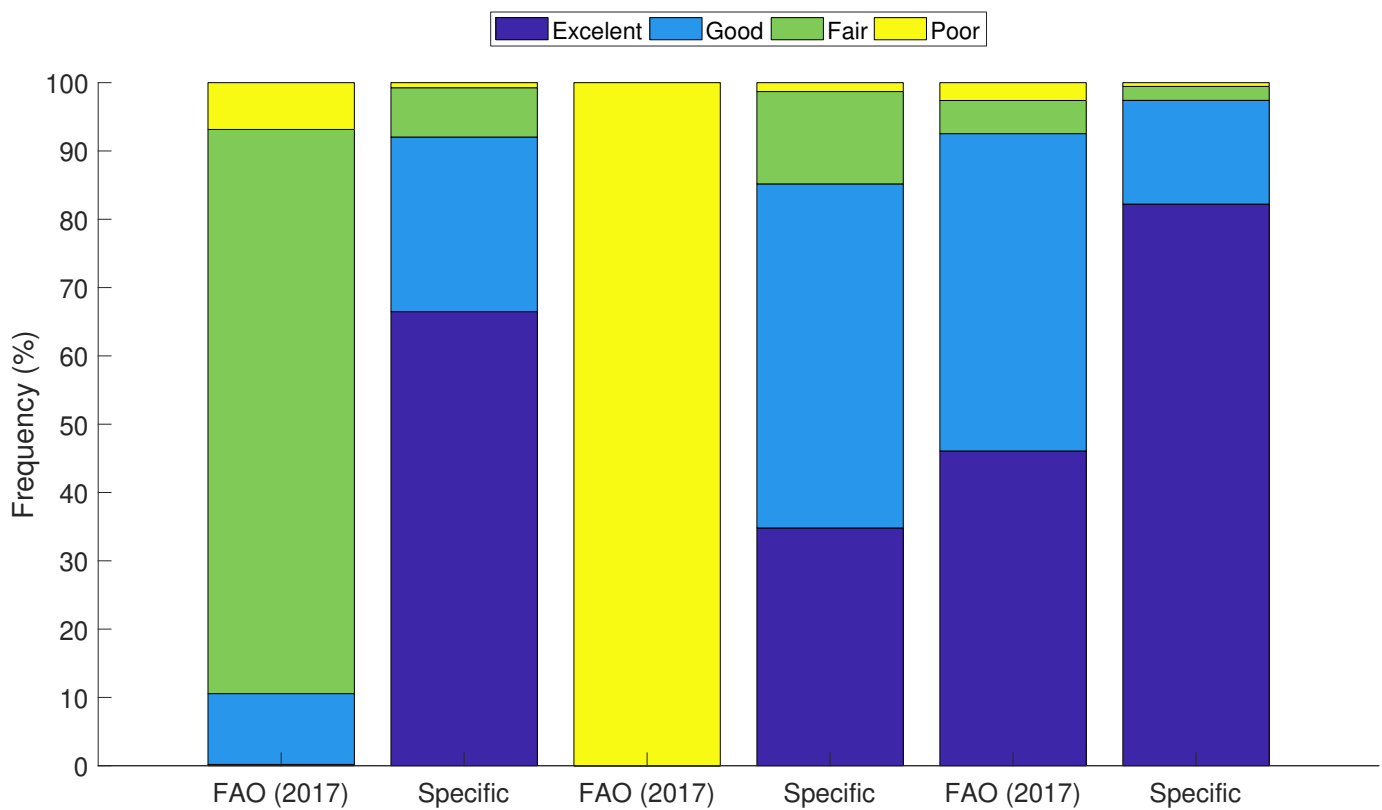

Figure 10. Comparison of the frequency of NRMSE values obtained by the proposed methodology and recommended by CROPWAT database [51].

\section{Conclusions}

We developed and assessed a methodology to estimate the Ky value under local conditions for a given crop, soil, weather, sowing date, and management, as well as for each growth stage, 
using AquaCrop-OS under Chilean conditions. The proposed methodology presented a good agreement; excellent simulation of $67 \%, 35 \%$, and $82 \%$ was observed for maize, sugar beet, and wheat, respectively (Figure 10), allowing us to estimate the $K y$ values under local conditions and to dispose of the typical simple mathematical approach in which yield reduction is estimated as a result of water scarcity at each growth stage.

Most irrigation managers consider resources to be available over the whole season. However, at sub-seasonal time scales-weekly, monthly, or even daily-irrigation managers and farmers must make decisions and take action based on new information regarding climate drivers and resource availability. Thus, the $K y$ value could be used to tailor water management strategies under changing conditions [27]. Future studies should focus on the estimation of $K y$ under a more diverse range of management scenarios.

Author Contributions: Conceptualization, M.K.-O., N.S., E.H., A.G.-F., O.M., and D.R.; Data curation, M.K.-O., N.S., E.H., O.M., and D.R.; Formal analysis, M.K.-O.; Investigation, M.K.-O., N.S., E.H., A.G.-F., O.M., and D.R.; Methodology, M.K.-O. and N.S.; Resources, D.R.; Software, M.K.-O., N.S., and O.M.; Supervision, N.S., E.H., A.G.-F., and D.R.; Visualization, M.K.-O.; Writing_-original draft, M.K.-O. All authors have read and agreed to the published version of the manuscript.

Funding: The research leading to this report was supported by the National Agency for Research and Development (ANID) through ANID-PCHA/National Doctorate/2015-21150463, the project ANID/FONDAP/15130015: Water Research Center for Agriculture and Mining (CRHIAM) and FONDECYT 1160656: Hillslope Water Storage and Runoff Processes: Linking Climate Variability And Interannual Storage.

Acknowledgments: Authors thank the project ANID/FONDAP/15130015: Water Research Center for Agriculture and Mining (CRHIAM), the Laboratory of Investigation and Technologies to the Water Management in the Agriculture (ItecMA ${ }^{2}$ ) and the Institute of Hydrology and Meteorology of the Dresden University of Technology.

Conflicts of Interest: The authors declare no conflict of interest.

\section{References}

1. FAO. AQUASTAT Website. FAO's Information System on Water and Agriculture; Food and Agriculture Organization of the United Nations: Rome, Italy, 2016.

2. Hubick, K.T.; Farquhar, G.D.; Shorter, R. Correlation between water use efficiency and carbon isotope discrimination in diverse peanut (Arachis) germplasm. Aust. J. Plant Physiol. 1986, 13, 803-816. [CrossRef]

3. Saccon, P. Water for agriculture, irrigation management. Appl. Soil Ecol. 2017. [CrossRef]

4. Malik, A.; Shakir, A.; Ajmal, M.; Khan, M.; Khan, T. Assessment of AquaCrop model in simulating sugar beet canopy cover, biomass and root yield under different irrigation and field management practices in semi-arid regions of Pakistan. Water Resour. Manag. 2017, 31, 4275-4292. [CrossRef]

5. Steduto, P.; Hsiao, T.; Raes, D.; Fereres, E. AquaCrop-The FAO crop model to simulate yield response to water: I. Concepts and underlying principles. Agron. J. 2009, 101, 426-437. [CrossRef]

6. Paredes, P.; de Melo-Abreu, J.; Alves, I.; Pereira, L.S. Assessing the performance of the FAO AquaCrop model to estimate maize yields and water use under full and deficit irrigation with focus on model parameterization. Agric. Water Manag. 2014, 144, 81-97. [CrossRef]

7. Nyakudya, I.W.; Stroosnijder, L. Effect of rooting depth, plant density and planting date on maize (Zea mays L.) yield and water use efficiency in semi-arid Zimbabwe: Modeling with AquaCrop. Agric. Water Manag. 2014, 146, 280-296. [CrossRef]

8. Heng, L.K.; Hsiao, T.; Evett, S.; Howell, T.; Steduto, P. Validating the FAO AquaCrop model for irrigated and water deficient field maize. Agron. J. 2009, 101, 488-498. [CrossRef]

9. Toumi, J.; Er-Raki, S.; Ezzahar, J.; Khabba, S.; Jarlan, L.; Chehbouni, A. Performance assessment of AquaCrop model for estimating evapotranspiration, soil water content and grain yield of winter wheat in Tensift Al Haouz (Morocco): Application to irrigation management. Agric. Water Manag. 2016, 163, 219-235. [CrossRef]

10. Mkhabela, M.S.; Paul, R.B. Performance of the FAO AquaCrop model for wheat grain yield and soil moisture simulation in Western Canada. Agric. Water Manag. 2012, 110, 16-24. [CrossRef]

11. Andarzian, B.; Bannayan, M.; Steduto, P.; Mazraeh, H.; Barati, M.E.; Barati, M.A.; Rahnama, A. Validation and testing of the AquaCrop model under full and deficit irrigated wheat production in Iran. Agric. Water Manag. 2011, 100, 1-8. [CrossRef] 
12. Alishiri, R.; Paknejad, F.; Aghayari, F. Simulation of sugarbeet growth under different water regimes and nitrogen levels by AquaCrop. Int. J. Biosci. 2014, 4, 1-9.

13. Stricevic, R.; Cosic, M.; Djurovic, N.; Pejic, B.; Maksimovic, L. Assessment of the FAO AquaCrop model in the simulation of rainfed and supplementally irrigated maize, sugar beet and sunflower. Agric. Water Manag. 2011, 98, 1615-1621. [CrossRef]

14. Montoya, F.; Camargo, D.; Ortega, J.; Córcoles, J.; Domínguez, A. Evaluation of AquaCrop model for a potato crop under different irrigation conditions. Agric. Water Manag. 2016, 164, 267-280. [CrossRef]

15. Garcia-Vila, M.; Fereres, E. Combining the simulation crop model AquaCrop with an economic model for the optimization of irrigation management at farm level. Eur. J. Agron. 2012, 36, 21-31. [CrossRef]

16. Araya, A.; Habtu, S.; Hagdu, K.M.; Kebede, A.; Dejene, T. Test of AquaCrop model in simulating biomass and yield of water deficient and irrigated barley (Hordeum vulgare). Agric. Water Manag. 2010, 97, 1838-1846. [CrossRef]

17. Geerts, S.; Raes, D.; Garcia, M.; Miranda, R.; Cusicanqui, J.A.; Taboada, C.; Mendoza, J.; Huanca, R.; Mamani, A.; Condori, O.; et al. Simulating yield response of quinoa to water availability with AquaCrop. Agron. J. 2009, 101, 499-508. [CrossRef]

18. Maniruzzaman, M.; Talukder, M.S.U.; Khan, M.H.; Biswas, J.C.; Nemes, A. Validation of the AquaCrop model for irrigated rice production under varied water regimes in Bangladesh. Agric. Water Manag. 2015, 159, 331-340. [CrossRef]

19. Jensen, J. Water consumption by agricultural plants. In Water Deficit and Plant Growth; Kozlowski, T., Ed.; Academic Press: New York, NY, USA, 1968; pp. 1-22.

20. Doorenbos, J.; Kassam, A. Yield Response to Water; FAO: Rome, Italy, 1979.

21. Carvallo, H.O.; Holzapfel, E.A.; Lopez, M.A.; Mariño, M.A. Irrigated cropping optimization. J. Irrig. Drain. Engin. ASCE 1998, 124, 67-72. [CrossRef]

22. Kipkorir, E.; Sahli, A.; Raes, D. MIOS: A decision tool for determination of optimal irrigated cropping pattern of a multicrop system under water scarcity constraints. Irrig. Drain. 2002, 51, 155-166. [CrossRef]

23. Raes, D.; Geerts, S.; Kipkorir, E.; Wellens, J.; Sahli, A. Simulation of yield decline as a result of water stress with a robust soil water balance model. Agric. Water Manag. 2006, 81, 335-357. [CrossRef]

24. Schütze, N.; de Paly, M.; Shamir, U. Novel simulation-based algorithms for optimal open-loop and closed-loop scheduling of deficit irrigation systems. J. Hydroinform. 2012, 14, 136-151. doi:10.2166/hydro.2011. 073. [CrossRef]

25. Singh, A. Optimal Allocation of Resources for the Maximization of Net Agricultural Return. J. Irrig. Drain. Eng. 2012, 138, 830-836. [CrossRef]

26. Banihabib, M.; Zahraei, A.; Eslamian, S. Dynamic programming model for the system of a non-uniform deficit irrigation and reservoir. Irrig. Drain. 2017, 66, 71-81. [CrossRef]

27. Kuschel-Otárola, M.; Rivera, D.; Holzapfel, E.; Palma, C.D.; Godoy-Faúndez, A. Multiperiod optimisation of irrigated crops under different conditions of water availability. Water 2018, 10, 1434. [CrossRef]

28. Steduto, P.; Hsiao, T.C.; Fereres, E.; Raes, D. Crop Yield Response to Water. FAO Irrigation and Drainage Paper 66; Food and Agriculture Organization of the United Nations: Rome, Italy, 2012; p. 503.

29. Karamouz, M.; Zahraie, B.; Kerachian, R.; Eslami, A. Crop pattern and conjuctive use management: A case study. Irrig. Drain. 2010, 59, 161-173. [CrossRef]

30. Shrestha, N.; Geerts, S.; Raes, D.; Horemans, S.; Soentjens, S.; Maupas, F.; Clouet, P. Yield response of sugar beets to water stress under Western European conditions. Agric. Water Manag. 2010, 97, 346-350. [CrossRef]

31. Kresović, B.; Tapanarova, A.; Tomić, Z.; Životić, L.; Vujović, D.; Sredojević, Z.; Gajić, B. Grain yield and water use efficiency of maize as influenced by different irrigation regimes through sprinkler irrigation under temperate climate. Agric. Water Manag. 2016, 169, 34-43. [CrossRef]

32. Djaman, K.; Irmak, S.; Rathje, W.R.; Martin, D.L.; Eisenhauer, D.E. Maize evapotranspiration, yield production function, biomass, grain yield, harvest index, and yield response factors under full and limited irrigation. Trans. ASABE 2013, 56, 273-293.

33. Kiymaz, S.; Ertek, A. Yield and quality of sugar beet (Beta vulgaris L.) at different water and nitrogen levels under the climatic conditions of Kirsehir, Turkey. Agric. Water Manag. 2015, 158, 156-165. [CrossRef]

34. Tarkalson, D.D.; King, B.A.; Bjorneberg, D.L. Yield production functions of irrigated sugarbeet in an arid climate. Agric. Water Manag. 2018, 200,1-9. [CrossRef] 
35. Bandyopadhyay, K.K.; Misra, A.K.; Ghosh, P.K.; Hati, K.M.; Mandal, K.G.; Moahnty, M. Effect of irrigation and nitrogen application methods on input use efficiency of wheat under limited water supply in a Vertisol of Central India. Irrig. Sci. 2010, 28, 285-299. [CrossRef]

36. Liu, X.W.; Shao, L.W.; Sun, H.Y.; Chen, S.Y.; Zhang, X.Y. Responses of yield and water use efficiency to irrigation amount decided by pan evaporation for winter wheat. Agric. Water Manag. 2013, 129, 173-180. [CrossRef]

37. Foster, T.; Brozovic, N.; Butler, A.; Neale, C.; Raes, D.; Steduto, P.; Fereres, E.; Hsiao, T. AquaCrop-OS: An open source version of FAO's crop water productivity model. Agric. Water Manag. 2017, 181, 18-22. [CrossRef]

38. MathWorks. Parallel Computing Toolbox: User's Guide; Technical report; The MathWorks, Inc.: Natick, MA, USA, 2017.

39. Raes, D.; Steduto, P.; Hsiao, T.C.; Fereres, E. Reference Manual: AquaCrop Plug-in Program (Version 4.0); Technical Report; FAO: Rome, Italy, 2012.

40. Loague, K.; Green, R.E. Statistical and graphical methods for evaluating solute transport models; overview and application. J. Contam. Hydrol. 1991, 7, 51-73. [CrossRef]

41. Jamieson, P.D.; Porter, J.R.; Wilson, D.R. A test of the computer simulation model ARC-WHEAT1 on wheat crops grown in New Zealand. Field Crop. Res. 1991, 27, 337-350. [CrossRef]

42. DGA. Diagnóstico y Clasificación de los Cursos y Cuerpos de Agua Según Objetivo y Calidad; Cuenca del río Itata: Santiago, Chile, 2004.

43. ODEPA. Región del Biobío: Información Regional 2018; Technical Report; Oficina de Estudios y Políticas Agrarias (ODEPA): Santiago, Chile, 2018.

44. Rivera, D.; Granda, S.; Arumí, J.L.; Sandoval, M.; Billib, M. A methodology to identify representative configurations of sensors for monitoring soil moisture. Environ. Monit. Assess. 2011, 184, 6563-6574. [CrossRef]

45. Granda, S.; Rivera, D.; Arumí, J.L.; Sandoval, M. Monitoreo continuo de humedad con fines hidrológicos. Tecnolog. Cienc. Agua 2013, 4, 189-197.

46. Rivera, D.; Sandoval, M.; Godoy, A. Exploring soil databases: A self-organizing map approach. Soil Use Manag. 2015, 31, 121-131. [CrossRef]

47. Faiguenbaum, H. Labranza, Siembra y Producción de los Principales Cultivos de Chile; Vivaldi y Asociados: Santiago, Chile, 2003; p. 760.

48. Allen, R.G.; Walter, I.A.; Elliott, R.; Itenfisu, D.; Brown, P.; Jensen, M.E.; Mecham, B.; Howell, T.A.; Snyder, R.; Eching, S.; et al. Task Committee on Standardization of Reference Evapotranspiration; SCE: Reston, VA, USA, 2005.

49. Van Genuchten, M.T.; Leij, F.J.; Yates, S.R. The RETC Code for Quantifying the Hydraulic Functions of Unsaturated Soils; EPA/600/2-91/065; U.S. Environmental Protection Agency: Ada, OK, USA, 1991; p. 85.

50. Kuschel-Otárola, M. Estimación de Flujos de Agua en un Andisol Usando Datos de Humedad. Bachelor's Thesis, Universidad de Concepción, Chillán, Chile, 2014.

51. FAO. “CROPWAT 8.0" Databases and Software; FAO: Rome, Italy, 2017.

(C) 2020 by the authors. Licensee MDPI, Basel, Switzerland. This article is an open access article distributed under the terms and conditions of the Creative Commons Attribution (CC BY) license (http:/ / creativecommons.org/licenses/by/4.0/). 